\title{
ORGANIZATIONAL PRACTICES OF CAREER MANAGEMENT AND THRIVING AT WORK: A MEDIATIONAL ROLE OF PSYCHOLOGICAL CAPITAL
}

\author{
Julia Aubouin-Bonnaventure, Séverine Chevalier, \& Evelyne Fouquereau \\ EE 1901 QualiPsy, University of Tours (France)
}

\begin{abstract}
In the 1980s, globalization and business competition led to an instability in work organizations which were no longer able to ensure stable and predictable careers. Responsibility of career management was transferred to workers. Consequently, research on the role of individuals in their career management became popular, while work investigating the role of organizations gradually declined. However, some studies have indicated that it remains beneficial for organizations to invest in practices of career management (PCM) for their employees through a supportive approach due to the link with positive outcomes for both employees and organizations. PCM refer to programs, processes, and other forms of assistance provided by organizations to support and enhance their employees' career success ( $\mathrm{Ng}$, Eby, Sorensen and Feldman, 2005) such as career planning, training and skills development programs, promotion, coaching, mentoring, annual appraisal interviews, retirement preparation programs or outplacements. At an individual level, the conservation of resources theory (Hobfoll, 2011) and the job demand resource model (Demerouti, Bakker, Nachreiner \& Schaufeli, 2001) postulate that resources of the professional environment, such as PCM, promote the preservation and development of personal resources and the employees' psychological health. While some studies have shown a link between PCM and indicators of hedonic well-being such as job satisfaction (e.g., Kooij, Ansen, Dikkers \& De Lange, 2010), work examining the links with indicators of eudemonic well-being, such as thriving at work, remains scarce. Moreover, previous studies have paid little attention to the psychological mechanism linking PCM to well-being at work. To fill this gap, our study focused on the synergy of psychological resources (i.e., self-efficacy, hope, optimism and resilience) defined as a core construct, known as PsyCap (Luthans, Avolio, Avey \& Norman, 2007). The sample consisted of 652 French people working in nonprofit, private and public organizations. Structural equation modeling suggested indirect effects of PCM on thriving at work through PsyCap (partial mediation) and this was confirmed with a bootstrapping procedure. Limitations of the study are discussed.
\end{abstract}

Keywords: Organizational practices of career management, thriving at work, psychological capital.

\section{Introduction}

In the 1970s, the traditional career concept was characterized by stability, job security, and structural and vertical advancement in organizations. Ten years later, the emergence of competition brought instability into the environment of organizations which had to downsize and restructure. As a consequence, organizations were no longer able to provide structured careers with a clear and predictable linear upward trajectory and transferred responsibility for career management to workers (De vos, Dewettinck \& Buyens, 2008). The study of the role of the individual in the management of his/her own career thus grew significantly (e.g., boundaryless careers and protean careers) to the detriment of the role of the organization (De vos \& Cambré, 2017). However, presently research is beginning to reconsider these practices because they are essential organizational resources for workers (e.g., Clarke, 2013). Studies have demonstrated that they are positively associated with workers' psychological health (De vos $\&$ al., 2009) and with objective (e.g., salary and promotion) and subjective career success (e.g., career satisfaction) ( $\mathrm{Ng}$ et al., 2005). Practices of career management (PCM) also promote individual performance such as sales (Yahya, Othman \& Meruda, 2012). The implementation and effectiveness of these practices therefore involve substantial issues for both workers and organizations.

\section{Background}

The field of study of PCM presents several challenges. First, there is a lack of coherence in the terms used to define them (e.g., organizational support for career development, organizational career management, traditional career management, perceived investment in worker development, prospects of 
career growth or development opportunities, Baruch, Szücs \& Gunz, 2015). Secondly, although several typologies of practices have been developed, none are consensual (e.g., Bagdalli \& Gianecchini, 2018; Baruch \& Peiperl, 2000). Consequently, defining PCM is not easy. However, the most frequently used definition is that proposed by $\mathrm{Ng}$ et al. (2005) who specified these practices as programs, processes, and other forms of assistance provided by organizations to support and enhance their employees' career success. These authors quote practices as diverse as training and skills development programs inside and outside the organization, skills management programs, career counseling, formal mentoring and coaching programs, individualized feedback, promotion, job rotation, outplacements, international assignments and retirement preparation programs ( $\mathrm{Ng}$ et al., 2005).

PCM can be considered as the caravan passageways of Hobfoll's Conservation of resources theory (2011), providing the environmental conditions that support, promote, enrich and protect the resources of individuals. These organizational resources generate the development of personal resources through a positive spiral. For example, Rego and Cunha (2009) found that these practices were positively associated with indicators of psychological health such as emotional well-being, happiness and work-family balance. Other studies have also observed positive relationships with a set of attitudes such as job satisfaction and affective engagement (Kooij et al., 2010), or positive behaviors such as organizational citizenship behaviors (Okurame, 2012). Finally, these practices have positive effects on subjective and objective indicators of career success, such as career satisfaction, promotion or wage progression ( $\mathrm{Ng} \&$ al., 2005). However, few studies have investigated the relationship between PCM and heudemonic indicators of well-being. Nevertheless, several of these indicators are attracting growing interest among the scientific community, such as thriving at work (e.g., Kleine, Rudolph \& Zacher, 2019).

Spreitzer et al. (2005) defined thriving at work as "the psychological state in which individuals experience both a sense of vitality and a sense of learning at work" (p.538). This definition covers two basic elements. First, the authors point out that thriving at work is a temporary state and not a durable disposition that is therefore malleable. Then, they emphasize that this state comes from the combined psychological experience of vitality and learning. On the one hand, vitality refers to the feeling of having available energy and feeling alive at work. This occurs when workers feel enthusiasm for their work and are passionate about what they do. On the other hand, learning is "the acquisition and application of knowledge and skills" and is observed when workers feel that they are continuously improving in their professional activity (Porath et al., 2012). Thriving at work is considered as a key resource for workers as it is an indicator of personal growth (Porath \& al., 2012; Spreitzer et al., 2005).

For Spreitzer et al. (2005) the central premise behind their model was that "when individuals are situated in particular work contexts, they are more likely to thrive" (P.539). Research has emphasized the need to identify the influence of organizational factors on this psychological state (e.g., Walumbwa, Muchiri, Misati, Wu \& Meiliani, 2018). In this context, while some factors such as HPWSs have already demonstrated positive links with thriving at work (Zhang, Xu, Jin \& Ford, 2018), no study has focused specifically on the influence of PCM. However, PMC are essential for workers because they allow them to broaden their skills and knowledge, to apply them to new situations, provide them with challenges and help them develop their full potential (Armstrong-Stassen \& Stassen, 2013). We therefore hypothesized that PCM would have a positive relationship with thriving at work (hypothesis 1).

The second aim of this study was to understand the mechanism underlying this relation. According to Ten Brummelhuis et Bakker (2012), organizational resources can also promote key resources, a specific kind of personal resources, which refer to management resources that facilitate the development of other resources. PsyCap can be considered in this way. Luthans and Youssef ( 2007) defined the latter as: an individual's positive psychological state of development that is characterized by: (1) having confidence (self-efficacy) to take on and put in the necessary effort to succeed at challenging tasks; (2) making a positive attribution (optimism) about succeeding now and in the future; (3) persevering toward goals and, when necessary, redirecting paths to goals (hope) in order to succeed; and (4) when beset by problems and adversity, sustaining and bouncing back and even beyond (resiliency) to attain success (Luthans \& Youssef, 2007, p. 334). Luthans and al. (2007) postulated that in theory the combination of these four personal resources generated a synergistic effect and formed the second-order factor of PsyCap. An individual with a strong sense of these four personal resources would expect good things to happen to them, make ambitious choices, perceive goals as challenges, plan more decisively for relevant plans of action, persevere in achieving goals despite difficulties and perceive failures as opportunities for growth (Luthans, 2002). Consequently, these persons would be more resistant faced with adversity and have the ability to maintain a stable equilibrium when they were exposed to significant threat, risk or harm (Luthans \& Youssef, 2007).

Several literature reviews and meta-analyzes show that there is little knowledge about the organizational antecedents of PsyCap due to the lack of studies on the subject (Avey, Reichard, Luthans \& Mhatre, 2011; Avey, 2014; Newman, Ucbasaran, Zhu \& Hirst, 2014). However, Luthans (2002) explained that a professional environment that challenged workers and helped them to achieve their professional and personal goals would be favorable to the development of their PsyCap. In addition, PsyCap should be developed through mastery experiences and social persuasion like positive feed-back 
on work (Luthans, 2002). PCM represent organizational support and allow workers to plan their career, develop their skills and knowledge and advance in the hierarchy, therefore we postulated that they would promote the development of PsyCap.

Regarding the consequences of PsyCap on the individual, Youssef-morgan and Luthans (2014) explain that these resources foster well-being because the latter is shaped by our cognitive and affective assessments. However, PsyCap is formed by positive evaluations of past, present and future events that are based on external expectations and positive internal capacities. The availability of PsyCap resources serves as an indicator of an overall appraisal of well-being. Numerous studies have thus demonstrated the link between PsyCap and health indicators such as job satisfaction or psychological well-being (e.g., Avey \& al., 2011). Finally, Kleine and al (2019) conducted a meta-analysis in which they revealed that for a panel of 13 studies PsyCap was positively correlated with thriving at work (i.e., .40).

Although several studies have already identified the mediating role of PsyCap between organizational resources and dimensions of well-being (e.g., Mazzeti, Guglielmi, Chiesa \& Mariani, 2016), to our knowledge its role linking PCM and thriving has never been tested. We therefore hypothesized that PsyCap mediated a positive relation between PCM and thriving at work (hypothesis 2).

\section{Objectives}

The aim of this study was to test a mediation model.

\section{Method}

\subsection{Procedure}

Questionnaires were distributed in several French companies with both online and paper versions. A cover letter informed potential participants that this study was confidential and voluntary. The data was collected over approximately six weeks.

\subsection{Participants}

The sample consisted of 652 French workers of which 524 were female $(80.4 \%)$ and 128 male $(19,6 \%)$. Their average age was 41.84 years old $(\mathrm{SD}=11.01$; range 15 to 69 years) and with an average job tenure of 9.26 years $(\mathrm{SD}=9.18) .473$ participants lived with a partner and 179 were single. Regarding contracts, $82.8 \%$ were permanent and $16.8 \%$ tempory. Full-time and part-time work represented $79 \%$ and $21 \%$ respectively. There were 298 people who worked in nonprofit organizations $(45.7 \%), 214$ in private organizations $(32.8 \%)$ and 136 in public organizations $(20.9 \%)$. Finally, $79.1 \%$ were non-managerial employees, $13.5 \%$ were middle managers and $6.9 \%$ were senior managers.

\subsection{Measure}

Participants completed a self-report questionnaire using a five-point Likert scale $(1=$ totally disagree, 5 = totally agree).

Practices of career management were assessed using a new scale (in progress; Aubouin-Bonnaventure, Fouquereau \& Chevalier) composed of 10-items. Results indicated an acceptable reliability $(\alpha .71)$.

Thriving at work was assessed using the 10-item scale of Porath and al. (2012) assessing the extent to which workers experience both a sense of vitality and a sense of learning at work. More precisely, learning and vitality were assessed with five items each. Like Porath and al. (2012), we computed a composite score for these two dimensions. Results indicated an acceptable reliability $(\alpha .89)$.

PsyCap was assessed with the short version (PCQ-12) of the Psychological Capital Questionnaire (PCQ-24) (Luthans, Youssef et al., 2007). More precisely, hope was assessed with four items, self-efficacy with three items, resilience with three items and optimism with two items. Results indicated an acceptable reliability for hope $(\alpha=.70)$ and self-efficacy $(\alpha=.83)$, and a relative reliability for resilience $(\alpha=.50)$ and optimism $(\alpha=.42)$.

\section{Statistical analysis and results}

First, preliminary analyzes demonstrated (Table 1 ) that PCM was positively related to thriving at work $(r=.45, \mathrm{p}<.05)$ and to PsyCap $(r=.36, \mathrm{p}<.05)$, and that PsyCap was positively related to thriving at work $(r=.58, \mathrm{p}<.05)$. 
Table 1. Means, standard deviations and correlations among the study variables.

\begin{tabular}{|c|c|c|c|c|c|c|c|c|c|c|c|c|}
\hline & & Mean & $\mathrm{SD}$ & 1 & 2 & 3 & 4 & 5 & 6 & 7 & 8 & 9 \\
\hline 1 & PGC & 3.59 & 0.72 & - & .36 & .18 & .33 & .41 & .18 & .45 & .44 & .39 \\
\hline 2 & PsyCap & 3.71 & 0.48 & & - & .69 & .83 & .79 & .76 & .58 & .49 & .60 \\
\hline 3 & Self-efficacy & 3.87 & 0.66 & & & - & .47 & .28 & .37 & .34 & .27 & .38 \\
\hline 4 & Hope & 3.72 & 0.54 & & & & - & .60 & .55 & .59 & .51 & .58 \\
\hline 5 & Optimism & 3.50 & 0.73 & & & & & - & .48 & .51 & .44 & .51 \\
\hline 6 & Resilience & 3.75 & 0.57 & & & & & & - & .36 & .28 & .39 \\
\hline 7 & Thriving at work & 3.75 & 0.61 & & & & & & & - & .94 & .92 \\
\hline 8 & Vitality & 3.78 & 0.71 & & & & & & & & - & .72 \\
\hline 9 & Learning & 3.71 & 0.60 & & & & & & & & & \\
\hline
\end{tabular}

Then, we performed structural equation modeling using AMOS Version 25. The model tested consisted of three latent variables and 25 observed variables.

The SEM estimates were generated with the maximum-likelihood estimation method. The goodness of fit indices for our model were acceptable: $\chi^{2}=824.49$ (263), $\mathrm{p}<.001$, CFI $=.92$, $\mathrm{SRMR}=.05, \mathrm{RMSEA}=.06$.

As shown in Figure 1, the results of structural equation modeling indicated that PCM was positively related to PsyCap $(\beta=.43 ; \mathrm{p}<.001)$, which was positively linked to thriving at work $(\beta=.63 ; \mathrm{p}<.001)$. The results also revealed that PCM had a direct significant positive effect on thriving at work $(\beta=.28 ; \mathrm{p}<.001)$. These results suggested an indirect effect of PCM on thriving at work through PsyCap (partial mediation). In order to assess the magnitude and significance of this indirect effect, we then adopted a bootstrap procedure. A confidence interval (95\%) was calculated using 5,000 generated samples. The results confirmed the indirect effect of PCM on thriving at work through PsyCap $(\beta=.27, \mathrm{SE}=.05,95 \% \mathrm{CI}=[.19$ to .38$])$.

\section{Figure 1. The mediation model.}

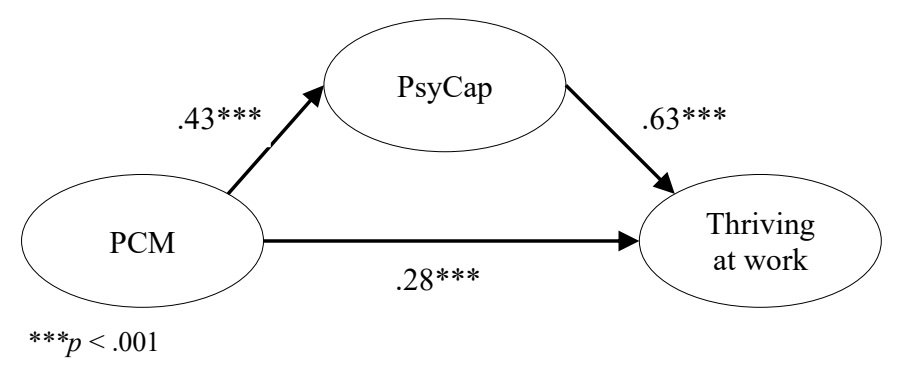

\section{Discussion and limits}

The results validated our hypothesis. PCM was positively associated with thriving at work (hypothesis 1) and this relationship was mediated by PsyCap (hypothesis 2). More precisely, the analyses demonstrated a partial mediation.

This study presents two major limitations. First, participants were essentially female and several studies have demonstrated differences in PCM perception according to gender (e.g., De Vos, Dewettinck $\&$ Buyens, 2009). Therefore, we recommend repeating this study with a more balanced sample. Second, analyses revealed weaknesses in the reliability of two sub-dimensions of the PsyCap (i.e., resilience and optimism).

\section{Conclusion}

The results of this study demonstrate that psychological health issues were associated with PCM for workers, organizations should therefore consider these practices (e.g., training and skills development programs, career counseling or mentoring) as one strategic axis of company policy for psychological health promotion and prevention.

\section{References}

Armstrong-Stassen, M., \& Stassen, K. (2013). Professional development, target-specific satisfaction, and older nurse retention. Career Development International, 18(7), 673-693.

Avey, J. B. (2014). The Left Side of Psychological Capital: New Evidence on the Antecedents of PsyCap. Journal of Leadership \& Organizational Studies, 21(2) 141-149. 
Avey, J. B., Reichard, R. J., Luthans, F., \& Mhatre, K. H. (2011). Meta-analysis of the impact of positive psychological capital on employee attitudes, behaviors, and performance. Human Resource Development Quarterly, 22(2), 127-152.

Bagdadli, S., \& Gianecchini, M. (2019). Organizational career management practices and objective career success: A systematic review and framework. Human Resource Management Review, 29(3), 353-370.

Baruch, Y., \& Peiperl, M. (2000). Career management practices: An empirical survey and implications. Human Resource Management, 39(4), 347-366.

Baruch, Y., Szücs, N., \& Gunz, H. (2015). Career studies in search of theory: the rise and rise of concepts. Career Development International, 20(1), 3-20.

Clarke, M. (2013). The organizational career: not dead but in need of redefinition. The International Journal of Human Resource Management, 24(4), 684-703.

De Vos, A., \& Cambré, B. (2017). Career Management in High-Performing Organizations: A Set-Theoretic Approach: Career Management in High-Performing Organizations: A Set-Theoretic Approach. Human Resource Management, 56(3), 501-518.

De Vos, A., Dewettinck, K., \& Buyens, D. (2008). To move or not to move?: The relationship between career management and preferred career moves. Employee Relations, 30(2), 156-175.

De Vos, A., Dewettinck, K., \& Buyens, D. (2009). The professional career on the right track: A study on the interaction between career self-management and organizational career management in explaining employee outcomes. European Journal of Work and Organizational Psychology, 18(1), $55-80$.

Demerouti, E., Bakker, A.B., Nachreiner, F. and Schaufeli, W.B. (2001a). The job demands-resources model of burnout. Journal of Applied Psychology, 86, 499-512.

Hobfoll, S. E. (2011). Conservation of resource caravans and engaged settings: Conservation of resource caravans. Journal of Occupational and Organizational Psychology, 84(1), 116-122.

Kleine, A., Rudolph, C. W., \& Zacher, H. (2019). Thriving at work: A meta-analysis. Journal of Organizational Behavior, 1-27.

Kooij, D. T. A. M., Jansen, P. G. W., Dikkers, J. S. E., \& De Lange, A. H. (2010). The influence of age on the associations between HR practices and both affective commitment and job satisfaction: A meta-analysis. Journal of Organizational Behavior, 31(8), 1111-1136.

Luthans, F. (2002). Positive organizational behavior: Developing and managing psychological strengths. Academy of Management Perspectives, 16(1), 57-72.

Luthans, F., Avolio, B. J., Avey, J. B., \& Norman, S. M. (2007). Positive Psychological capital: measurement and relationship with performance and satisfaction. Personnel Psychology, 60(3), 541-572.

Mazzetti, G., Guglielmi, D., Chiesa, R., \& Mariani, M. G. (2016). Happy employees in a resourceful workplace: just a direct relationship?: A study on the mediational role of psychological capital. Career Development International, 21(7), 682-696.

Newman, A., Ucbasaran, D., Zhu, F., \& Hirst, G. (2014). Psychological capital: A review and synthesis. Journal of Organizational Behavior, 35(S1), S120-S138.

Ng, T. W. H., Eby, L. T., Sorensen, K. L., \& Feldman, D. C. (2005). Predictors of objective and subjective career success: a meta-analysis. Personnel Psychology, 58(2), 367-408.

Okurame, D. (2012). Impact of career growth prospects and formal mentoring on organisational citizenship behaviour. Leadership \& Organization Development Journal, 33(1), 66-85.

Porath, C., Spreitzer, G., Gibson, C., \& Garnett, F. G. (2011). Thriving at work: Toward its measurement, construct validation, and theoretical refinement. Journal of Organizational Behavior, 33, 250-275.

Spreitzer, G., Sutcliffe, K., Dutton, J., Sonenshein, S., \& Grant, A. M. (2005). A Socially Embedded Model of Thriving at Work. Organization Science, 16(5), 537-549.

ten Brummelhuis, L. L. \& Bakker, A.B. (2012). A Resource Perspective on the Work-Home Interface: the work-home resources model. American Psychologist, 67(7), 545-56.

Walumbwa, F. O., Muchiri, M. K., Misati, E., Wu, C., \& Meiliani, M. (2018). Inspired to perform: A multilevel investigation of antecedents and consequences of thriving at work. Journal of Organizational Behavior, 39(3), 249-261.

Yahya, K. K., Othman, S. Z., \& Meruda, N. (2004). Relationship between organization career management and individual performance. International Journal Management Sciences, 11(2), 73-90.

Youssef-Morgan, C. M., \& Luthans, F. (2015). Psychological Capital and Well-being: Psychological Capital and Well-being. Stress and Health, 31(3), 180-188.

Zhang, Y., Xu, S., Jin, J., \& Ford, M. T. (2018). The within and cross domain effects of work-family enrichment: A meta-analysis. Journal of Vocational Behavior, 104, 210-227. 